\title{
The output stage of an operational amplifier on GaAs n-channel field-effect and GaAs p-n-p bipolar transistors with nonlinear negative feedback
}

This paper was downloaded from TechRxiv (https://www.techrxiv.org).

\section{LICENSE}

CC BY 4.0

SUBMISSION DATE / POSTED DATE

$16-12-2021 / 21-12-2021$

\section{CITATION}

Zhuk, Alexey; Prokopenko, Nikolay; Pakhomov, Ilya; Titov, Alexey (2021): The output stage of an operational amplifier on GaAs n-channel field-effect and GaAs p-n-p bipolar transistors with nonlinear negative feedback. TechRxiv. Preprint. https://doi.org/10.36227/techrxiv.17241191.v1

$\mathrm{DOI}$ 


\title{
The output stage of an operational amplifier on GaAs n-channel field-effect and GaAs p-n-p bipolar transistors with nonlinear negative feedback
}

\author{
Zhuk A. A. ${ }^{1}$, Prokopenko N. N. ${ }^{1}$, Pakhomov I. V. ${ }^{1}$, Titov A. E. ${ }^{2}$ \\ ${ }^{1}$ Don State Technical University, Rostov-on-Don, Russia \\ ${ }^{2}$ Southern Federal University, Rostov-on-Don, Russia \\ *E-mail: Alexey.zhuk96@mail.ru, ORCID: 0000-0002-7116-5924.
}

\begin{abstract}
:
A new circuit of the output stage of an operational amplifier implemented on GaAs n-channel field-effect transistors with a control p-n junction and GaAs bipolar p-n$\mathrm{p}$ transistors is investigated. Its peculiarity consists in the presence of a nonlinear negative feedback that stabilizes the drain current of the output transistor with an nchannel at a negative input voltage. The basic equations for the static mode of the output stage are given. The results of modeling in the LTspice simulation software of 3 modifications of the proposed circuit solutions are discussed.
\end{abstract}

Keywords: operational amplifier, output stage, GaAs JFET, GaAs BJT, analog microcircuitry, LTspice.

\section{Introduction}

A significant number of circuits of output stages (OS) of operational amplifiers (Op-Amp) are known, which are implemented on complementary bipolar (BJT) and field-effect (JFET, CMOS, SOI, SOS, etc.) transistors [2-28]. The above-mentioned OS circuit solutions are most popular in analog microcircuits implemented on the basis of standard technological processes [2-28].

In modern microcircuitry technology, there are a number of instrumentation tasks for extreme operating conditions (exposure to low temperatures and penetrating radiation). To solve them, it is promising to use circuit solutions, including Op-Amp with OS, based on GaAs basic matrix crystals [29].

The features of the existing GaAs technological processes [30-33] impose significant restrictions on the OS circuitry of this subclass. This is due to the types of transistors being implemented and their characteristics. In particular, the GaAs technological process of the "Minsk Scientific Research Institute of Radio Materials" (https://mniirm.by) is focused on the manufacture of analog circuits containing only field-effect GaAs transistors with a control p-n junction and bipolar 
GaAs p-n-p transistors. Thus, there are a number of restrictions on the circuitry of analog devices when using this technological process.

The purpose of the article is to consider the proposed GaAs OS circuitry of this subclass and perform their computer modeling in the LTspice simulation software.

The purpose and novelty of the article is to consider the proposed GaAs circuitry of the OS of the Op-Amp and perform its computer simulation in the LTspice simulation software.

Fig. 1 shows a scheme of a well-known silicon OS, which was used as a prototype of the proposed GaAs OS [1].

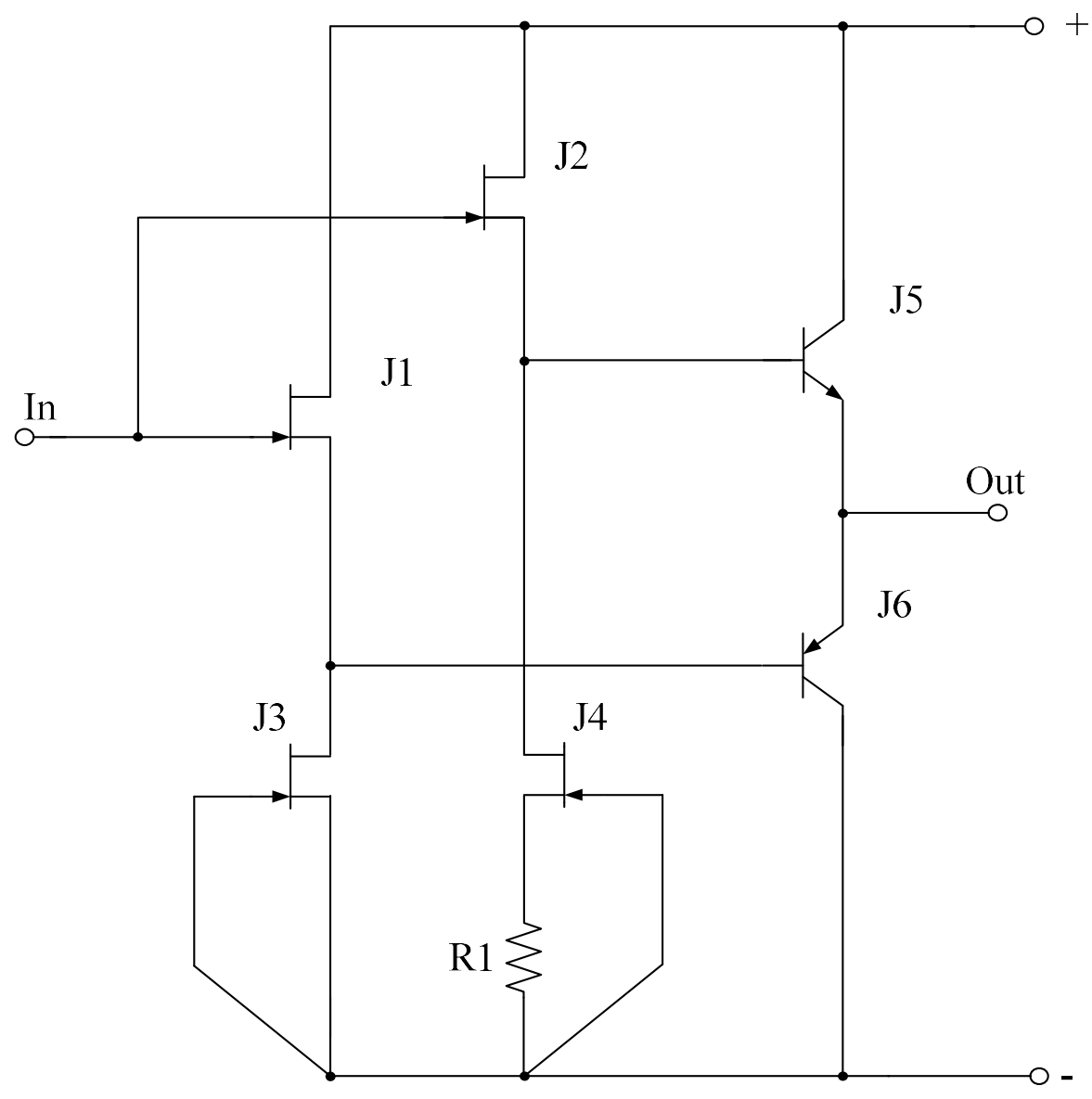

Fig. 1 - Scheme of the well-known BiJTJFet silicon OS Op-Amp [1]

A significant disadvantage of the OS in Fig. 1 is that it cannot be implemented on the basis of technological processes that allow creating only GaAs JFET field-effect transistors with a control $p-n$ junction and GaAs bipolar $p-n-p$ transistors (https://mniirm.by). 


\section{The scheme of the proposed OS}

Fig. 2 shows the scheme of the proposed OS [1]. The resistor $\mathrm{R}_{\text {load }}$ in Fig. 2 and further simulates the properties of the OS load.

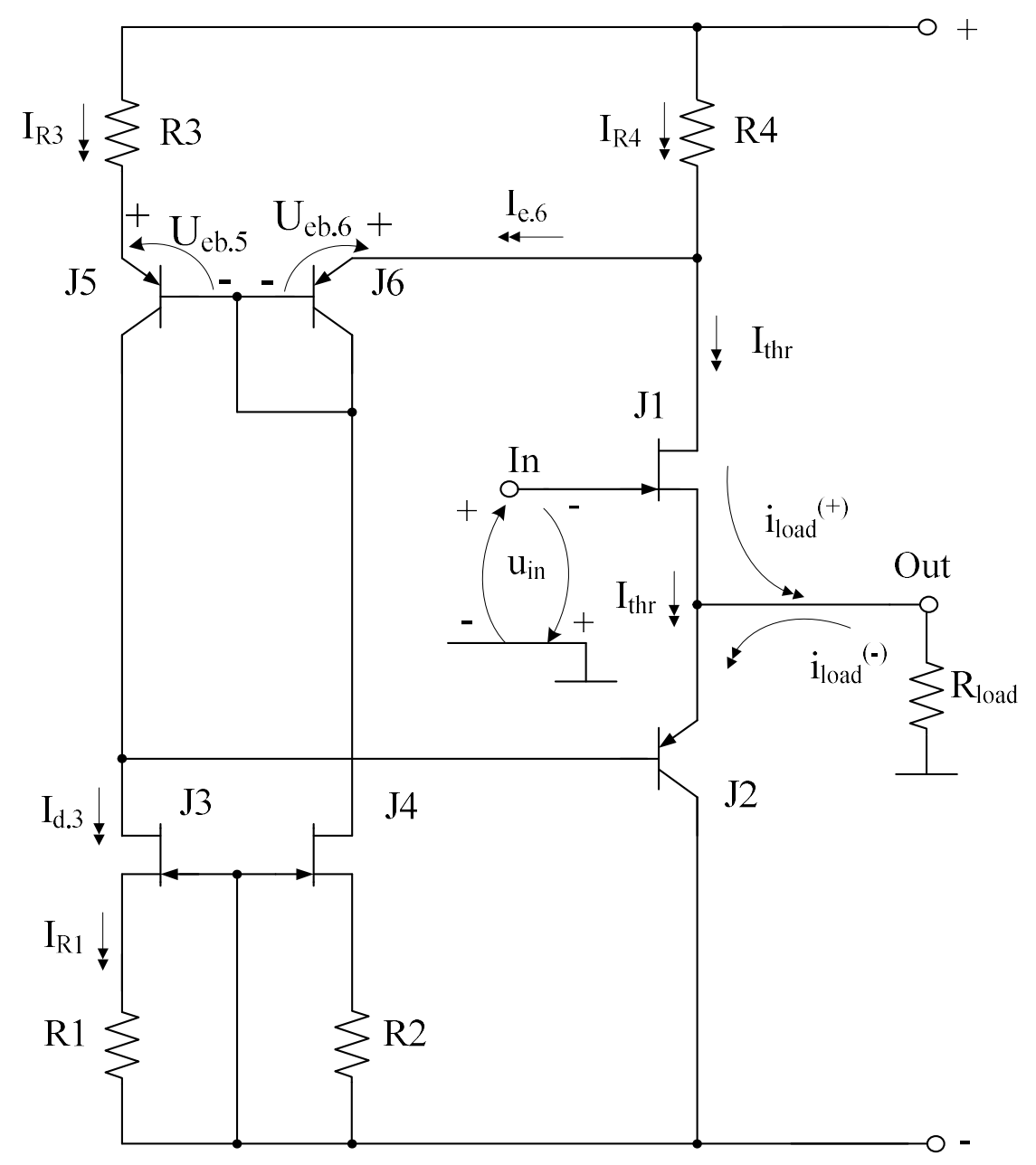

Fig. 2 - Scheme of GaAs OS Op-Amp [1]

If a positive input voltage $u_{i n}^{(+)}$is applied to the OS input in Fig. 2, then an output current $\mathrm{i}_{\text {load }}^{(+)}$is formed in the load $\mathrm{R}_{\text {load, }}$, the maximum value of which $\mathrm{I}_{\text {load..max }}{ }^{(+)}$is determined by the maximum permissible current of the source of the field-effect transistor J1. In this case, using the J5 transistor, the base of the output bipolar transistor $\mathrm{J} 2$ is locked along the circuit, which can be excluded from further consideration of the operation of the circuit in this mode. When several elementary field-effect transistors are switched on in parallel as a J1 transistor (or its channel width is increased), the numerical values of the maximum current $\mathrm{I}_{\text {load..max }}{ }^{(+)}$can be increased to the set values.

With a negative increment of the input voltage OS, the current in the load $\mathrm{R}_{\text {load }}$ is provided by the output bipolar transistor J2. Due to the decrease in the drain 
current of the field-effect transistor $\mathrm{J} 1$, the static collector current of the bipolar transistor J5 decreases, which leads to an increase in the base current of the output transistor $\mathrm{J} 2$ and the output current in the load $\mathrm{R}_{\text {load }}$ with a negative $\mathrm{u}_{\mathrm{in}}^{(-)}$. As a consequence, the maximum negative current in the load $\mathrm{R}_{\text {load }}$ will be determined by the maximum drain current of the transistor J3:

$$
\mathrm{I}_{\text {load.max }}{ }^{(-)}=\beta_{2} \mathrm{I}_{\mathrm{d} .3},
$$

where, $\beta_{2}$ is the current gain of the base of the transistor $\mathrm{J} 2 ; \mathrm{I}_{\mathrm{d} .3}=\mathrm{U}_{\mathrm{gs.3}} / \mathrm{R}_{1}$ is the static current of the $\mathrm{J} 3 ; \mathrm{U}_{\mathrm{gs.3}}$ is gate-source voltage of the $\mathrm{J} 3$ field-effect transistor.

At the same time, due to the negative feedback, the current of the source of the field-effect transistor $\mathrm{J} 1$ practically does not change $\left(\mathrm{I}_{\mathrm{s} .1} \approx \mathrm{const}\right)$ and, consequently, the increment of the output voltage in this OS mode corresponds to the increment of its input voltage $u_{i n}^{(-)}$. As a consequence, the maximum negative current in the load $\mathrm{R}_{\text {load }}$ will be determined by equation (1).

In static mode $\left(\mathrm{R}_{\text {load }}=1 \mathrm{M} \Omega, \mathrm{u}_{\mathrm{in}}=0\right)$, the following currents and voltages are set in Fig. 2:

$$
\mathrm{U}_{\mathrm{eb} .5}+\mathrm{I}_{\mathrm{d} .3} \mathrm{R}_{3}=\mathrm{U}_{\mathrm{eb} .6}+\mathrm{R}_{4}\left(\mathrm{I}_{\mathrm{e} .6}+\mathrm{I}_{\mathrm{thr}}\right) \text {, }
$$

where $\mathrm{U}_{\text {eb.5, }} \mathrm{U}_{\text {eb.6 }}$ - the emitter-base voltages of bipolar transistors J5, J6; $\mathrm{I}_{\text {thr }}$ - through current $\mathrm{OS}$ at $\mathrm{R}_{\text {load }}=1 \mathrm{M} \Omega ; \mathrm{R}_{1}, \mathrm{R}_{3}, \mathrm{R}_{4}$ - resistance of resistors $\mathrm{R} 1, \mathrm{R}$, $\mathrm{R} 4 ; \mathrm{I}_{\mathrm{e} .6}-$ static current of the emitter of the bipolar transistor J6.

It follows from equation (2) that for $\mathrm{I}_{\mathrm{d} .3}=$ const, $\mathrm{I}_{\mathrm{e} .6}=$ const, $\mathrm{U}_{\mathrm{eb} .5} \approx \mathrm{U}_{\mathrm{eb} .6}$, due to the choice resistance of resistors R3, R4 in the circuit in Fig. 2, the set values of the through current $\mathrm{I}_{\text {thr }}$ are set.

The peculiarity of the proposed OS scheme in Fig. 2 is the presence of a general negative feedback relative to the Out, which ensures a high linearity of the amplitude characteristic - the absence of a dead zone characteristic of the wellknown OS class "AB".

Fig. 3 shows the scheme of the proposed GaAs OS Op-Amp for the case when transistors $\mathrm{J} 3, \mathrm{~J} 4$ are made according to a cascode structure. This increases the loop gain along the negative feedback circuit of the OS, and reduces the influence of voltage instabilities on the power supply's buses. 


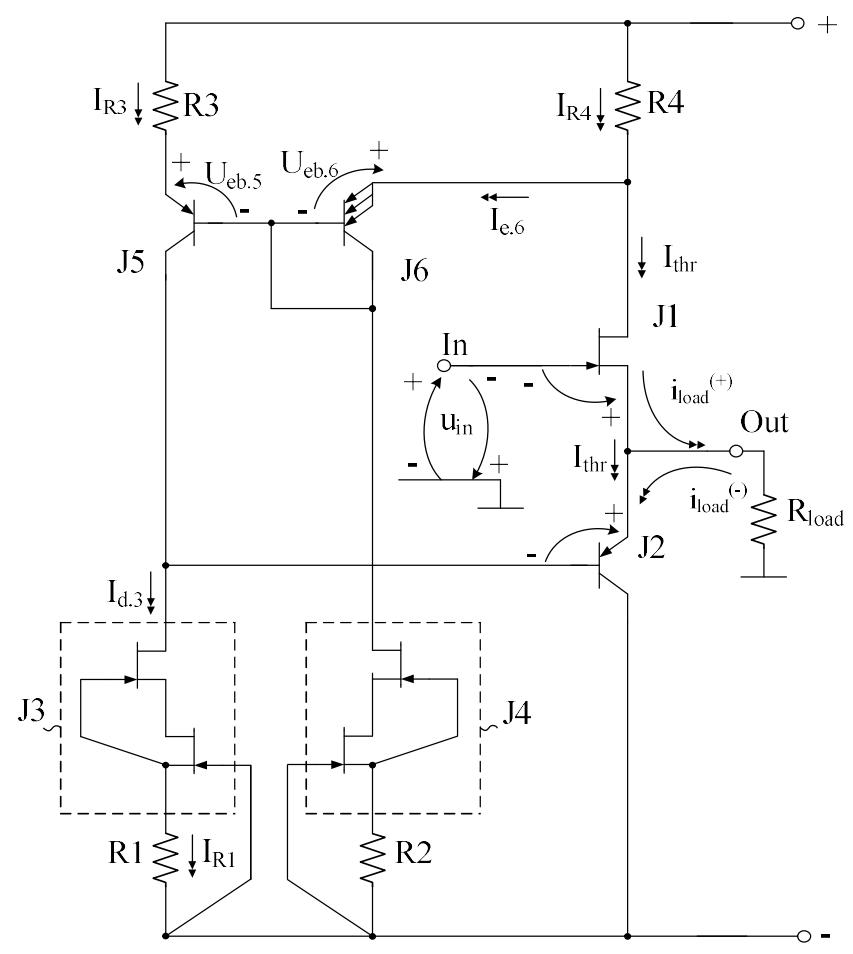

Fig. 3 - Cascode structure of GaAs OS Op-Amp

A source voltage repeater (VR) is introduced into the circuit in Fig. 4, which increases the loop gain along the negative feedback circuit of the OS, and also allows you to obtain higher values of the maximum current in the load $\mathrm{I}_{\text {load..max }}{ }^{(-)}$.

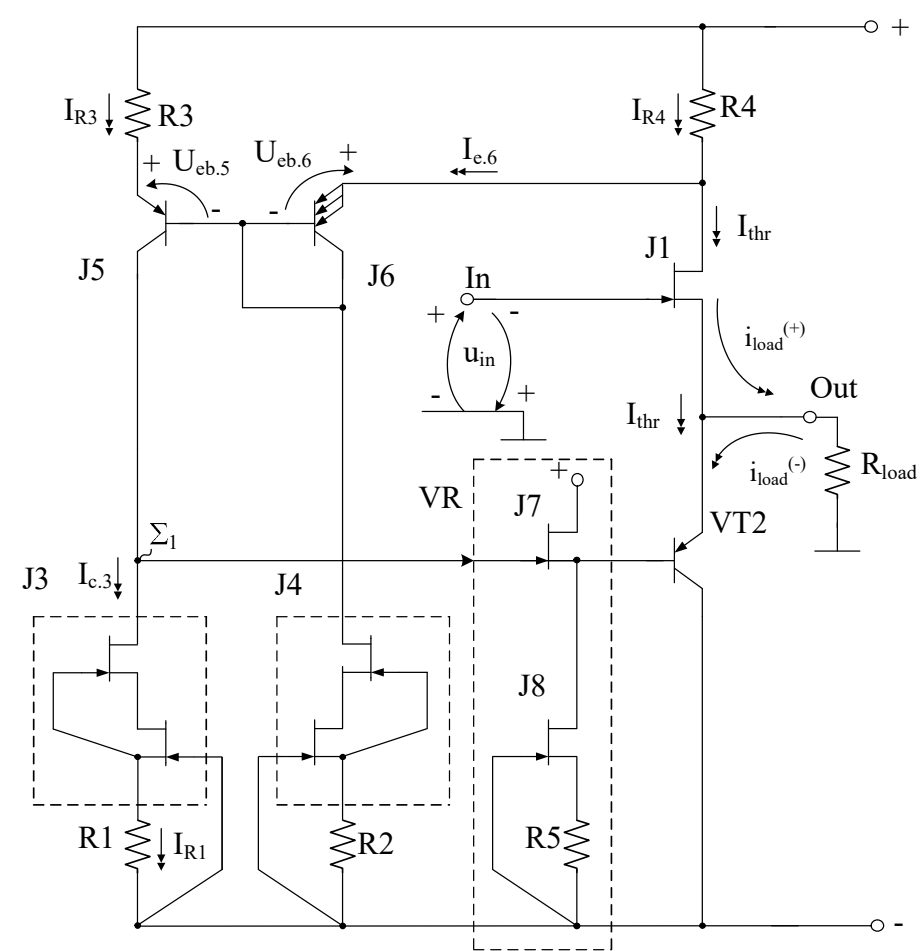

Fig. 4 - Scheme of GaAs OS Op-Amp with high $\mathrm{I}_{\text {load..max }}{ }^{(-)}$ 
To reduce the numerical values of the resistance of the resistor $\mathrm{R} 4$, the bipolar transistor J6 in the circuits in Fig. 3 and Fig. 4 can be made in the form of parallel inclusion of several elementary bipolar transistors. In this case, the numerical values of the resistance of the resistor R4 can be measured in tens or hundreds of ohms.

\section{Computer simulation results}

Fig. 5 shows a scheme for modeling GaAs OS in Fig. 2 in an LTspice simulation software at $\mathrm{t}=27^{\circ} \mathrm{C}, \mathrm{R} 1=350 \Omega, \mathrm{R} 2=150 \Omega, \mathrm{R} 3=11.5 \mathrm{k} \Omega, \mathrm{R} 4=5.4 \mathrm{k} \Omega$, $+\mathrm{vcc}=-\mathrm{vee}=10 \mathrm{~V}, \mathrm{R}_{\mathrm{load}}=1 \mathrm{M} \Omega$, static voltage at the input OS V1 $=-1.2 \mathrm{~V}$.

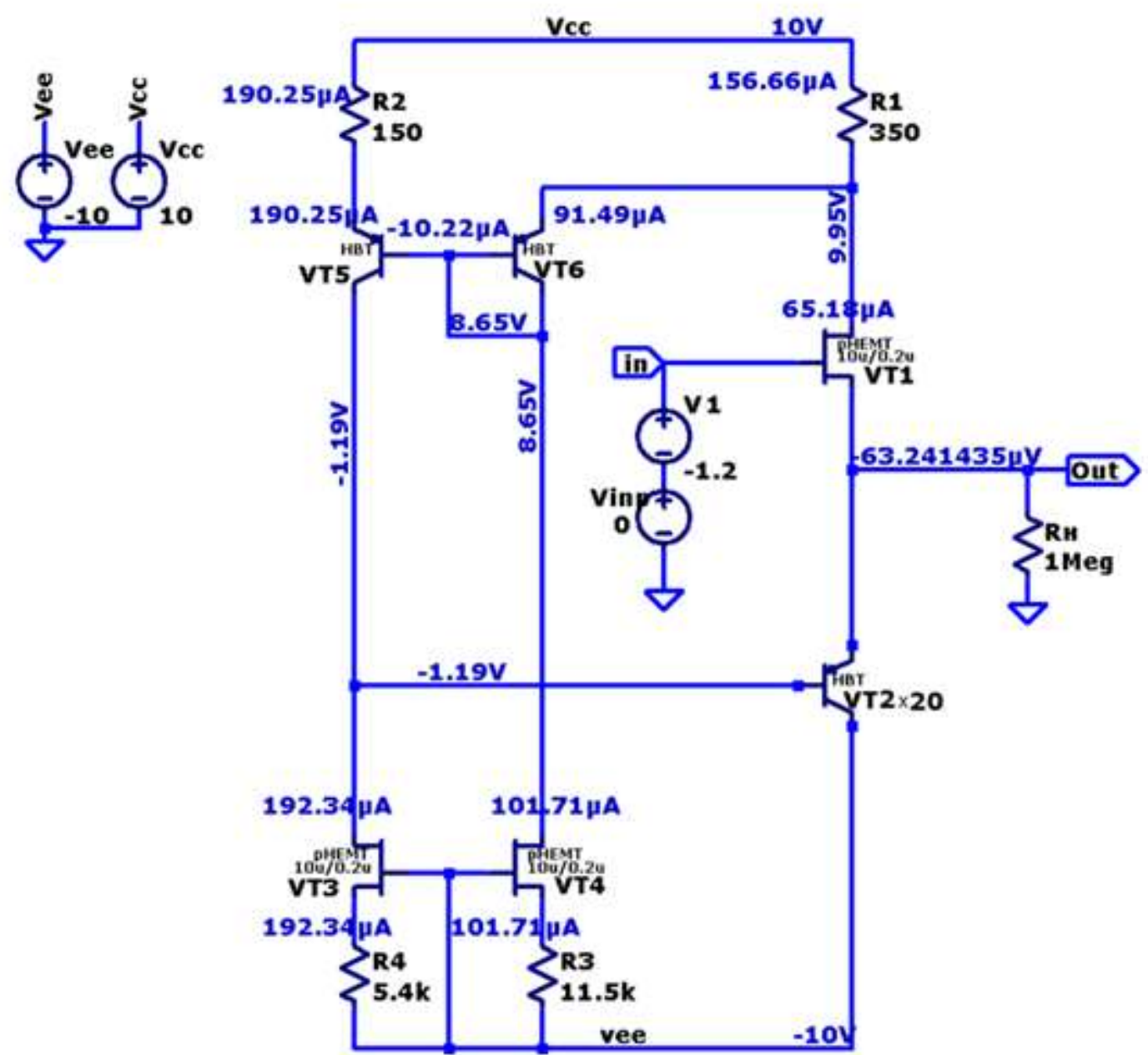

Fig. 5 - Scheme for modeling GaAs OS in Fig. 2 in the LTspice simulation software

Fig. 6 shows the amplitude characteristic of the OS in Fig. 5 at $\mathrm{t}=27^{\circ} \mathrm{C}$, $\mathrm{R} 1=350 \Omega, \mathrm{R} 2=150 \Omega, \mathrm{R} 3=11.5 \mathrm{k} \Omega, \mathrm{R} 4=5.4 \mathrm{k} \Omega,+\mathrm{vcc}=$-vee $=10 \mathrm{~V}, \mathrm{R}_{\text {load }}=5 \mathrm{k} \Omega /$ $20 \mathrm{k} \Omega / 1 \mathrm{M} \Omega$, static voltage at the input OS V1 $=-1.2 \mathrm{~V}$. 


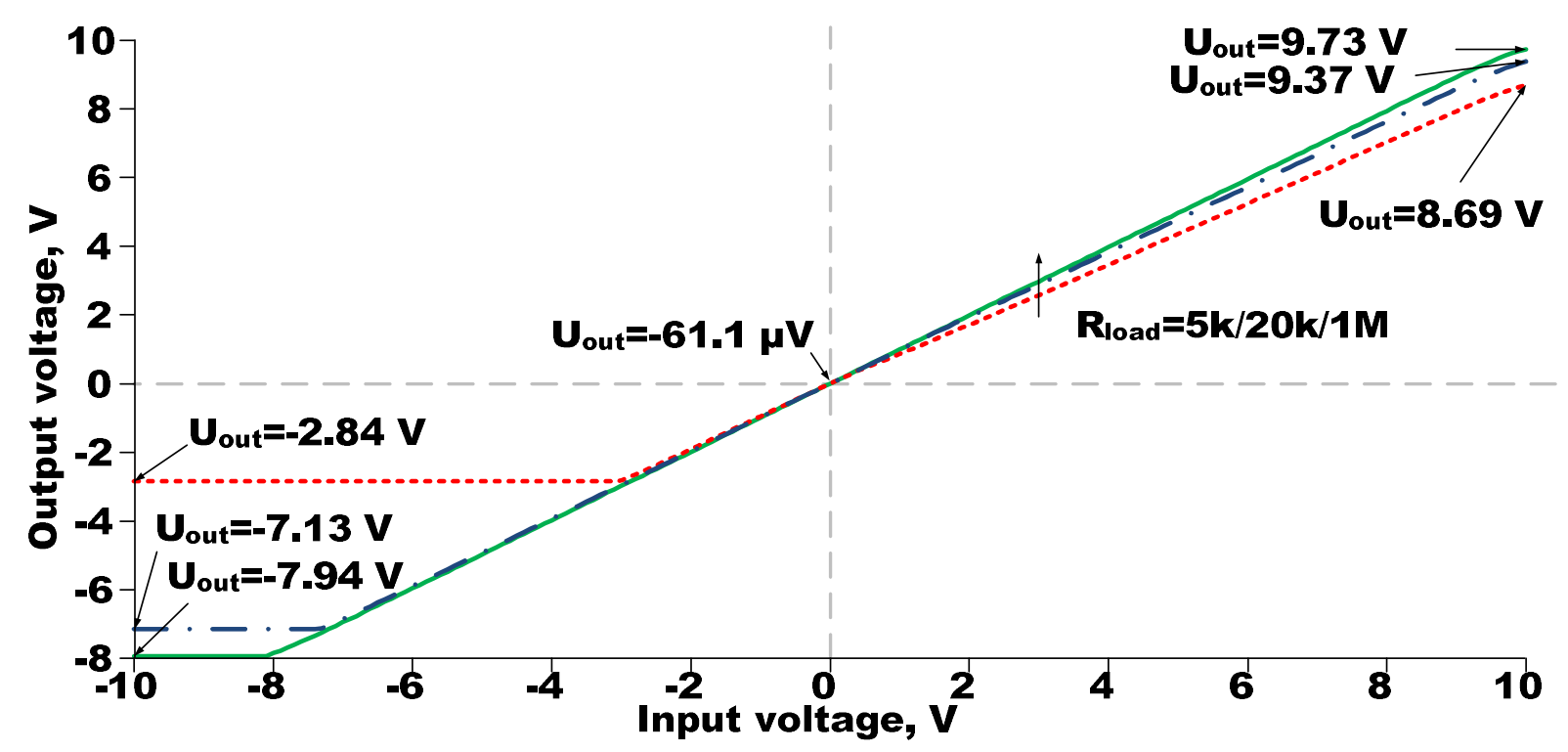

Fig. 6 - Amplitude characteristic of the OS of Fig. 5 at $\mathrm{t}=27^{\circ} \mathrm{C}$

Fig. 7 shows the scheme for the simulation of GaAs OS in Fig. 4 in the LTspice simulation software at $\mathrm{t}=27{ }^{\circ} \mathrm{C}, \mathrm{R} 1=350 \Omega, \mathrm{R} 2=150 \Omega, \mathrm{R} 3=5.4 \mathrm{k} \Omega$, $\mathrm{R} 4=11.5 \mathrm{k} \Omega, \mathrm{R} 5=5 \mathrm{k} \Omega, \mathrm{R}_{\text {load }}=1 \mathrm{M} \Omega$, $+\mathrm{vcc}=-\mathrm{vee}=10 \mathrm{~V}$, the static voltage at the input OS V1=-1.17 V.

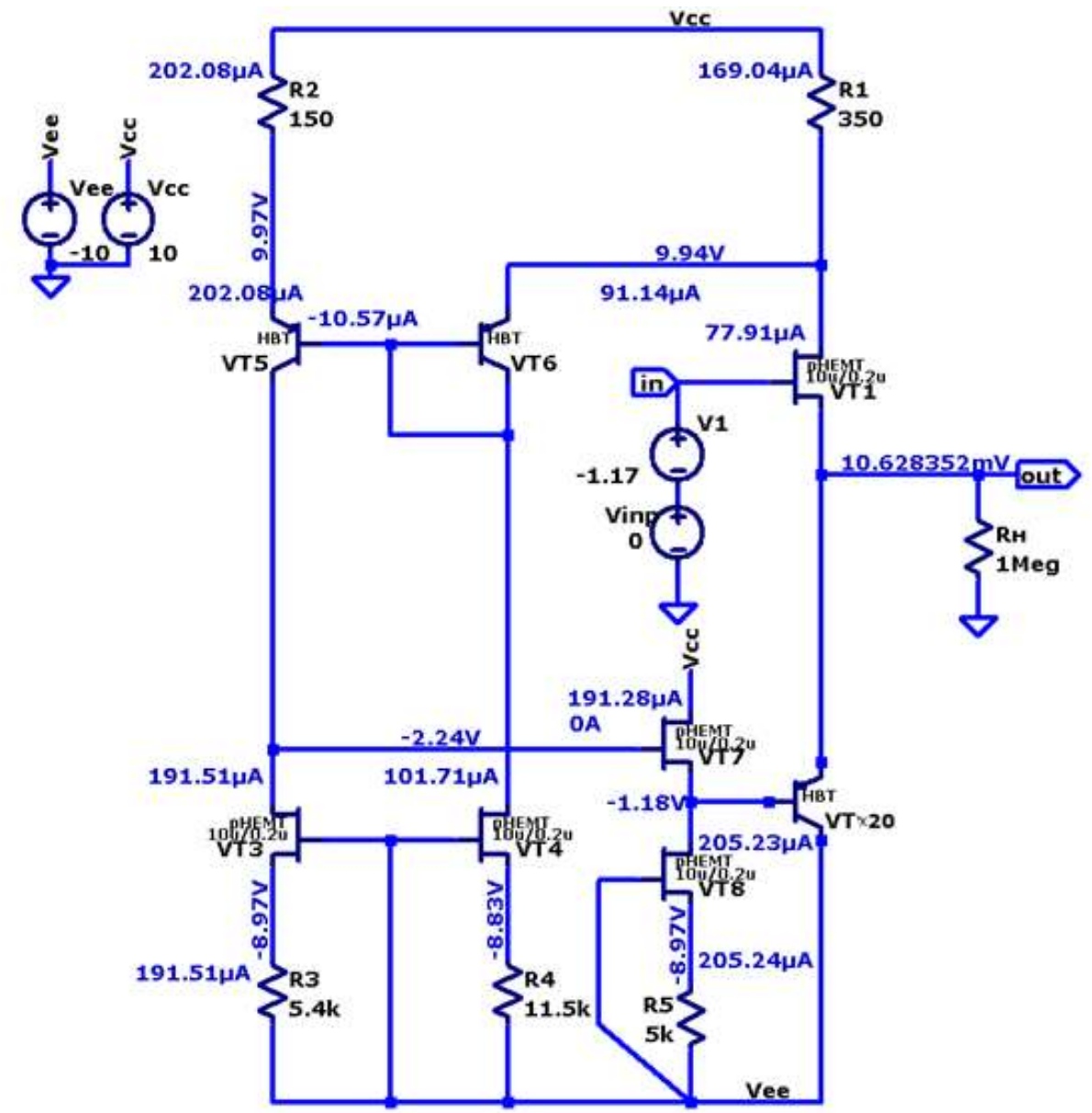

Fig. 7 - Scheme for simulating the GaAs OS of Fig. 4 in the LTspice simulating software 
Fig. 8 shows the amplitude characteristic OS in Fig. 7 at $\mathrm{t}=27{ }^{\circ} \mathrm{C}$, $\mathrm{R} 1=350 \Omega, \mathrm{R} 2=150 \Omega, \mathrm{R} 3=5.4 \mathrm{k} \Omega, \mathrm{R} 4=11.5 \mathrm{k} \Omega, \mathrm{R} 5=5 \mathrm{k} \Omega,+\mathrm{vcc}=-\mathrm{vee}=10 \mathrm{~V}$, $\mathrm{R}_{\text {load }}=2 \mathrm{k} \Omega / 20 \mathrm{k} \Omega / 1 \mathrm{M} \Omega$, static voltage at the input OS V1=-1.17 V.

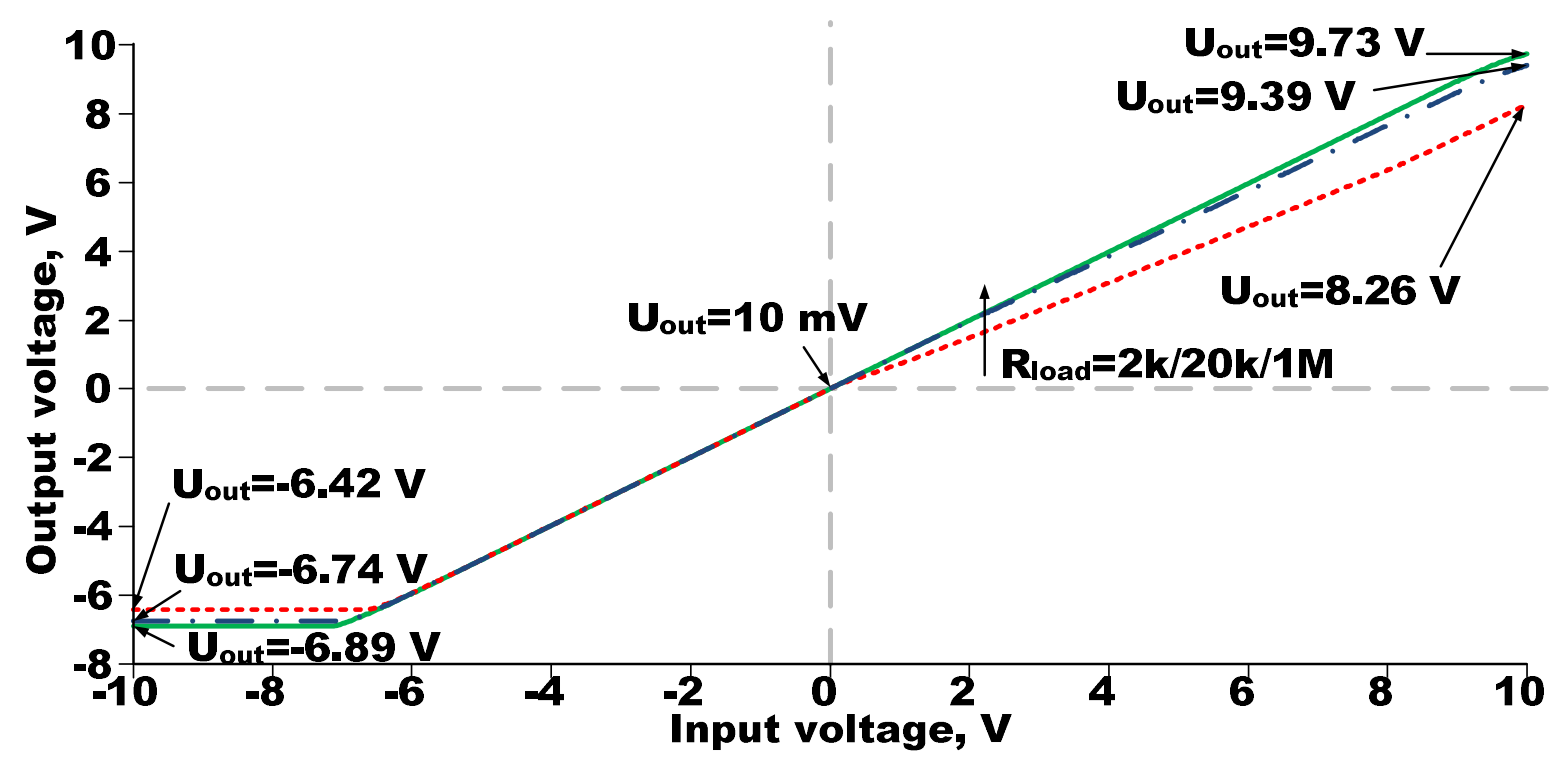

Fig. 8 - Amplitude characteristic of the OS of Fig. 7 for $\mathrm{t}=27^{\circ} \mathrm{C}$

\section{Conclusion}

Computer modeling (Fig. 5 - Fig. 8) shows that the proposed GaAs OS [1], whose circuitry is adapted for use in the low temperature range and the effects of penetrating radiation [28], has significant advantages in comparison with the known options for constructing OS when they are implemented on silicon JFET field-effect transistors with a control p-n junction and bipolar p-n-p transistors.

The research has been carried out at the expense of the Grant of the Russian Science Foundation (project No. 18-79-10109-P).

\section{References}

1. A. A. Zhuk, A. A. Pavlyuchik, N. N. Prokopenko, I. V. Pakhomov, "Gallium arsenide output stage of the power amplifier," (in Russian), RU Patent Appl. 2021126637, Sept. 09, 2021.

2. O. V. Dvornikov, N. N. Prokopenko, P. S. Budyakov, N. V. Butyrlagin, "The output stage of the power amplifier based on complementary transistors," (in Russian), RU Patent 2523947C1, July 27, 2014, fig. 4. 
3. N. N. Prokopenko, O. V. Dvornikov, A. V. Bulgakova, P.S. Budyakov, "The output stage of the BIJFet operational amplifier," (in Russian), RU Patent 2668981C1, Oct. 5, 2018.

4. E. V. Ovsepyan, A.A. Zhuk, N.N. Prokopenko, "Bipolar-field effect buffer amplifier," (in Russian), RU Patent 2677401C1, Jan. 16, 2019.

5. S. Vogel, S. Lehr, "Circuit for limiting the output swing of an amplifier," WO Patent Appl. 2007135139A1, Nov. 29, 2007.

6. N. R. Scheinberg, "JFET current mirror and voltage level shifting apparatus," U.S. Patent 4743862A, May 10, 1988.

7. R. B. Heineke, S. A. Olson, D. P. Swart, G. W. Swift, "Fully balanced transimpedance amplifier for high speed and low voltage applications," U.S. Patent 6433638B1, Aug. 13, 2002, fig. 1a-2.

8. S. Wada, Y. Watanabet, "Feedback amplifier having amplified signal path and feedback signal path separated," U.S. Patent Appl. 20050253653A1, Nov. 17, 2005.

9. G. P. Vella-Coleiro, "Symmetric integrated amplifier with controlled DC offset voltage," U.S. Patent 4825174A, Apr. 25, 1989, fig.3, fig.6.

10. Y. M. Kobzev, V. I. Staroselsky, V. I. Suetinov, "Amplifier stage," (in Russian), RU Patent 2099856C1, Dec. 12, 1997, fig. 3.

11. G. D. McCormack, "Differential amplifier with common-mode bias feedback," U.S. Patent 4904953A, Feb. 27, 1990, fig. 2.

12. M. Tada, Y. Sasaoka, T. Abe, A. Iwasaka, T. Kimura, S. Shino, "Sheet transporting apparatus and sheet processing apparatus using the same," U.S. Patent 7896339B2, Mar. 1, 2011, fig. 4.

13. K. Suzuki, “Operational amplifier,” U.S. Patent 6342814B1, Jan. 29, 2002.

14. C. Cozzolino, "Super source follower output impedance enhancement," U.S. Patent Appl. 20100182086A1, Jul. 22, 2010.

15. K. W. Kobayashi, "Compact monolithic wide band HEMT low noise amplifiers with regulated self-bias," U.S. Patent 5387880A, Feb. 7, 1995, fig. 1.

16. K. A. Reindel, T. J. Mego, "JFET ohmic differential amplifier," U.S. Patent 4598253A, Jul. 1, 1986.

17. L. M. de Weckdel, "High-speed full differential amplifier with common mode rejection," U.S. Patent 4667165A, May 19, 1987, fig. 2.

18. J. G. Graeme, S. D. Millaway, "Differential common base amplifier with feed forward circuit," U.S. Patent 4596958A, Jun. 24, 1986.

19. P. P. Siniscalchi, "High-swing folded cascode having a novel gain-boost amplifier," U.S. Patent 7116172B2, Oct. 3, 2006, fig. 4, fig. 5. 
20. S. Nagaya, H. Sugawara, T. Watanabe, "Amplifying circuit for an integrated circuit with low-noise characteristic," U.S. Patent 5648743A, Jul. 15, 1997.

21. K. Yamamoto and K. Maemura, "Quadrature modulator having phase shift and amplitude compensation circuits," U.S. Patent 5367271A, Nov. 22, 1994, fig. 2.

22. J. E. Bartling and D. A. Heaton, "Biasing circuits for field effect transistors using GaAs FETS," U.S. Patent 5065043A, Nov. 12, 1991, fig. $1 \mathrm{f}$.

23. T. Okayama, "Biasing circuits for field effect transistors using GaAs FETS," U.S. Patent Appl. 20070115056A1, May 24, 2007, fig. 2.

24. G. Zhang and F. Meng, "Differential amplifier having an improved slew rate," U.S. Patent 7548117B2, Jun. 16, 2009, fig. 5.

25. A. L. Limberg, "Voltage-followers with low offset voltages," U.S. Patent 4420726A, Dec. 13, 1983, fig. 1 - fig. 3.

26. P. Horowitz and U. Hill, The art of circuit engineering. Cambridge, MA, USA: Cambridge University Press, 2015.

27. P. Boonyaporn and V.Kasemsuwan, "A High Performance Class AB CMOS Rail to Rail Voltage Follower" in 2002 IEEE Asia-Pacific Conference, Yokohama, Japan, Oct. 6-10, 2002, pp. 161-163.

28. N.N. Prokopenko et al., The element base of radiation-resistant informationmeasuring systems: monograph. Shakhty, Rostov-on-Don, Russia: SRSUES, 2011 (in Russian).

29. O.V. Dvornikov, A.A. Pavlyuchik, N.N. Prokopenko et al. "Gallium Arsenide Analog Base Crystal," in Problems of developing promising microand nanoelectronic systems (MES), Moscow, Zelenograd, Mar.-Nov. 2021, pub. 2, pp. 47-54 (in Russian).

30. M. Fresina, "Trends in GaAs HBTs for wireless and RF," in 2011 IEEE Bipolar/BiCMOS Circuits and Technology Meeting, Atlanta, GA, USA, 2011, pp. 150-153.

31. P. J. Zampardi, M. Sun, C. Cismaru and J. Li, "Prospects for a BiCFET IIIV HBT Process," in 2012 IEEE Compound Semiconductor Integrated Circuit Symposium (CSICS), La Jolla. CA, USA, Oct. 14-17, 2012, pp. 1-3.

32. W. Liu, D. Hill, D. Costa and J. S. Harris, "High-performance microwave AlGaAs-InGaAs Pnp HBT with high-DC current gain," in IEEE Microwave and Guided Wave Letters. vol. 2, no. 8, Aug. 1992, pp. 331-333.

33. Peatman W. et al. InGaP-Plus ${ }^{\mathrm{TM}}$, "Advanced GaAs BiFET technology and applications," presented at the CS MANTECH Conference. Austin, Texas, USA, May 14-17, 2007, pp. 243-246. 